\title{
Empirical Analysis of Gray Relational Analysis of Employment Structure and Industrial Structure in Guangdong Province
}

\author{
Bing Wu \\ School of Economics, Jinan University, Guangzhou, China \\ Email: wubing614@163.com
}

How to cite this paper: Wu, B. (2017) Empirical Analysis of Gray Relational Analysis of Employment Structure and Industrial Structure in Guangdong Province. Journal of Human Resource and Sustainability Studies, 5, 47-56.

https://doi.org/10.4236/jhrss.2017.51005

Received: February 17, 2017

Accepted: March 11, 2017

Published: March 14, 2017

Copyright $\odot 2017$ by author and Scientific Research Publishing Inc. This work is licensed under the Creative Commons Attribution International License (CC BY 4.0).

http://creativecommons.org/licenses/by/4.0/

\begin{abstract}
This paper mainly uses the gray relational analysis method to analyze the effect of the upgrading of industrial structure and the internal structure of the three industries on the employment of labor force in Guangdong Province. Based on the empirical analysis, this paper puts forward the promotion of the present situation in Guangdong Province suggestions for healthy development of employment.
\end{abstract}

\section{Keywords}

Employment Structure, Industrial Structure, Gray Correlation

\section{Introduction}

Since the reform and opening up, Guangdong Province has made full use of policy advantages and regional advantages, with low labor cost "comparative advantage" to participate in the international division of labor, through the develop ment of labor-intensive industries to achieve rapid economic development, and long-term economic dominance. After the financial crisis, Guangdong export-oriented economy is facing difficulties, labor-intensive industries unsustainable, and Guangdong industrial structure is facing a new round of transformation and upgrading [1]. At the same time, the coexistence of migrant workers' labor shortage and employment problems of college students shows that the industrial structure and employment structure of Guangdong are not harmonious. How to realize the coordinated development of the employment structure in the transformation and upgrading of the industrial structure has become an important problem in the economic development of Guangdong. As one of the provinces ahead of the reform, Guangdong's economic development is typical, and it 
is of great practical significance to the analysis of the coordination of industrial structure and employment structure in Guangdong, and it also has important reference value for the coordinated development of industrial structure and employment structure in other provinces. This paper will try to use the economic data from 1978 to 2015 to study the coordination of employment structure and industrial structure in Guangdong Province.

This paper is divided into three parts. The first part mainly analyzes the evolution of industrial structure and employment structure in Guangdong Province. The second part uses the gray correlation analysis method to analyze the relationship between industrial structure and employment structure in Guangdong Province. The third part is based on the empirical analysis, combined with the development of Guangdong Province, and puts forward feasible policy recommendations.

\section{The Current Situation of Industrial Structure and Employment Structure in Guangdong Province}

\subsection{An Analysis of Industrial Structure in Guangdong Province}

Since the reform and opening up, the economic development of Guangdong Province has made remarkable achievements. The GDP of the region has increased from RMB 18.585 billion in 1978 to RMB 2,728,155 million in 2015. At the same time, the industrial structure of Guangdong Province has evolved. Between 1978 and 2015, the proportion of output value of primary industry showed a downward trend, the proportion of the output value of the secondary industry remained basically fluctuated between $40 \%-50 \%$, and the proportion of output value of tertiary industry showed a continuous growth trend. In 1985, the proportion of the output value of the tertiary industry in Guangdong Province exceeded that of the first industry for the first time. The three industrial structures changed from 29.8:46.6:23.6 in 1978 to 29.8:39.8:30.4 in 1985, and the industrial structure evolved into "two, three, one" from the original "two, one, three". By the year 2000, the proportion of the three industrial structures has evolved to 9.2:46.5:44.3, and "two, three, one" structure is further strengthened. In year 2001, the proportion of the tertiary industry for the first time more than the secondary industry, and form a short-term "three, two, one" industrial structure. Since 2003, due to the proportion of the primary industry output value and the proportion of the tertiary industry decreased, and back to the "two, three, one" industrial structure; by 2013, three industrial structure adjustment of 4.9: 47.3:47.8, the tertiary industry with a slight advantage over the secondary industry, so that the evolution of the three industrial structure upgrades to "three, two, one" structure, industrial structure once again ushers in an important conversion upgrade. It can be seen from Figure 1 that in the process of adjusting the industrial structure of Guangdong Province, the second and the third industry have become the main driving force of the growth of GDP, and the importance of the tertiary industry has become more and more obvious. 


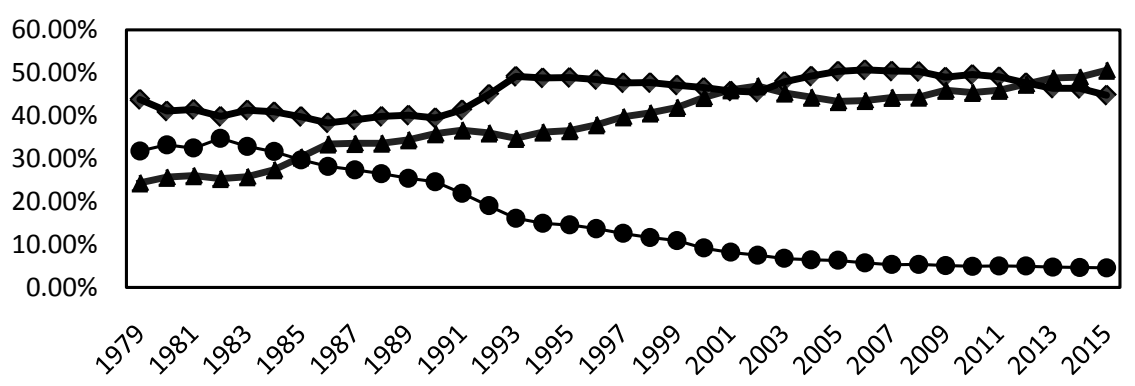

Figure 1. Evolution trend of industrial structure in Guangdong Province from 1978 to 2015. Source: according to the "Guangdong Statistical Yearbook" data compiled.

\subsection{An Analysis of the Employment Structure of Labor Force in Guangdong Province}

Since the reform and opening up more than 30 years, with the rapid economic development of Guangdong Province, China's largest labor into the province. In 1978, the proportion of employment in the first industry in Guangdong Province remained at a high level of $73.6 \%$. The proportion of employment in the secondary and tertiary industries was $13.8 \%$ and $12.6 \%$ respectively. The gap between the primary industry and the secondary and tertiary industries was significant, Since the beginning of 1978, with the Guangdong industrial structure of the continuous adjustment and upgrading, the flow of workers also continue to optimize the upgrade; Table 1 can be seen, the proportion of the primary industry employment was basically In 2000, the proportion of employment in the tertiary industry in Guangdong Province for the first time more than the secondary industry, the employment structure from the " 123 " to " 132 " to upgrade; the proportion of employment in the second and third industry is in a steady upward stage; In 2003, the proportion of employment in the first, second and third industries was 34.7:36.9:28.4, and the proportion of the second industry was higher than that of the tertiary industry. In 2004, the proportion of employment in the first, second and third industries was 34.7:36.9:28.4. The proportion of employees in the tertiary industry for the first time more than the first industry $30.4 \%$ of the proportion of employment, the initial employment structure showing the "two, three, one" situation, indicating that Guangdong Province has long been part of the employment structure from the industrial structure of the situation has gradually changed; by 2015, the number of employment in Guangdong Province from 1978 to 22,759,500 people rose to 6219.31 million, Among them, the number of employed persons in the first, second and tertiary industries was 13.775 million, 25.499 million, 2294.9 million, accounting for $22.1 \%, 41 \%$ and $36.9 \%$ of the total employment of the whole society. "Three, one" employment structure pattern; and, in 2011, the proportion of secondary industry employment reached a peak value of $42.4 \%$, starting in 2012 , the proportion of employment in the secondary industry showed a slight downward trend, while the tertiary industry is to maintain an upward trend. This shows that the employment structure in Guangdong Province is constantly adjusting to adapt to the upgrading of industrial structure. 
Table 1. Employment structure of three industries in Guangdong Province from 1978 to 2015.

\begin{tabular}{lcccc}
\hline Year & $\begin{array}{c}\text { Number of } \\
\text { employed persons/ } \\
\text { Million people }\end{array}$ & $\begin{array}{c}\text { The proportion of } \\
\text { employment in the } \\
\text { primary industry }\end{array}$ & $\begin{array}{c}\text { The proportion of } \\
\text { employment in the } \\
\text { secondary industry }\end{array}$ & $\begin{array}{c}\text { The proportion of } \\
\text { employment in the } \\
\text { tertiary industry }\end{array}$ \\
\hline 1978 & 2275.95 & 73.70 & 13.70 & 12.60 \\
1980 & 2367.78 & 70.70 & 17.10 & 12.20 \\
1985 & 2731.11 & 60.30 & 22.50 & 17.20 \\
1990 & 3118.10 & 53.00 & 27.20 & 19.80 \\
1995 & 3551.20 & 41.50 & 33.80 & 24.70 \\
2000 & 3989.32 & 39.90 & 28.00 & 32.10 \\
2005 & 5022.97 & 32.10 & 38.10 & 29.80 \\
2006 & 5177.02 & 30.20 & 38.90 & 30.90 \\
2007 & 5341.50 & 29.20 & 39.40 & 31.40 \\
2008 & 5471.72 & 27.90 & 39.70 & 32.40 \\
2009 & 5688.62 & 26.60 & 40.30 & 33.10 \\
2010 & 5870.48 & 24.40 & 42.40 & 33.20 \\
2011 & 5960.74 & 23.90 & 42.40 & 33.70 \\
2012 & 5965.95 & 23.80 & 42.00 & 34.20 \\
2013 & 6117.68 & 23.00 & 41.90 & 35.10 \\
2014 & 6183.23 & 22.40 & 41.40 & 36.20 \\
2015 & 6219.31 & 22.10 & 41.00 & 36.90 \\
\hline
\end{tabular}

On the whole, Guangdong Province, the adjustment of modern industrial structure optimization, coupled with the capital knowledge and technology and other elements continue to increase, resulting in the development of the first industry in Guangdong Province not only did not increase employment, but led to labor savings. The economic growth of the secondary industry has a strong ability to absorb the labor force, which reflects the characteristics of employment structure in Guangdong Province. The economic growth of the tertiary industry is relatively stable and the absorptive capacity of the labor force is not prominent. In summary, the employment structure in Guangdong Province has maintained a 2311 employment structure [2] [3].

\section{An Empirical Analysis of Gray Relational Analysis of Employment Structure and Industrial Structure in Guangdong Province}

\subsection{The Construction Mechanism of the Model}

Gray correlation analysis is a multi-factor statistical analysis method created by Professor Deng Julong in 1982, that is, through the quantitative analysis and comparative analysis of the geometric relations of the statistical data of the developmental change system, and then determine the superiority of the system bad factors, this method is not required on the number of samples, the calcula- 
tion is small, do not need a typical distribution. The core is to calculate the correlation coefficient. In general, the calculation of the degree of correlation first to the original data processing, and then calculate the correlation coefficient, which calculated the degree of relevance, discharge the order [4]. The detailed method and calculation steps of gray relational analysis are as follows:

The first step, establish the reference series and comparison series. Establish the dependent variable reference sequence (the parent sequence) $X_{0}(K), X_{0}=\left(X_{0}(1), X_{0}(2), X_{0}(3), \cdots X_{0}(K)\right)$, and the independent variable comparison sequence (the subsequence) $X_{i}(K)(I=1,2,3 \cdots k)$, and $X_{I}=\left\{X_{I}(1), X_{I}(2), X_{I}(3) \cdots X_{I}(k)\right\}$, and the $k$ is the sequence length.

The second step, we can do the number of non-dimensional processing. We can use the initialization method to eliminate the effects of various series of different dimensions. Then we can get a new series. This is $X i=\left\{X_{I}(1) / X_{I}(1), X_{I}(2) / X_{I}(1), X_{I}(3) / X_{I}(1), \cdots, X_{I}(N) / X_{I}(1)\right\}$.

The third step, calculate the correlation coefficient. The relevance is essentially a difference in the geometric properties of the curve, so the degree of correlation between the curves can be measured. The eliminated dimension series $X_{0}(t)$, $X_{i}(t)$, If the two sequences are at the same time $k$, the values are respectively $\left\{X_{0}(t), X_{i}(t)\right\}$, which is

$$
\begin{gathered}
X_{0}(t)=\left\{X_{0}(1), X_{0}(2), X_{0}(3), \cdots, X_{0}(K)\right\} \\
X_{i}(t)=\left\{X_{i}(1), X_{i}(2), X_{i}(3), \cdots, X_{i}(k)\right\}
\end{gathered}
$$

Remember $\Delta_{i}=\left|X_{0}(K)-X_{i}(k)\right|, i=1,2,3, \cdots, k$. The minimum value of each moment is recorded as $\Delta_{\min }$. The maximum is recorded as $\Delta_{\max }$.

$$
\begin{aligned}
\Delta_{\min } & =\min \left|X_{0}(i)-X_{1}(i)\right| \\
& =\min \left\{\left|X_{0}(1)-X_{1}(1)\right|,\left|X_{0}(2)-X_{1}(2)\right|, \cdots,\left|X_{0}(n)-X_{1}(n)\right|\right\} \\
\Delta_{\max } & =\max \left|X_{0}(i)-X_{1}(i)\right| \\
& =\max \left\{\left|X_{0}(1)-X_{1}(1)\right|,\left|X_{0}(2)-X_{1}(2)\right|, \cdots,\left|X_{0}(n)-X_{1}(n)\right|\right\}
\end{aligned}
$$

The correlation coefficient is calculated as follows:

$$
r=\frac{\Delta_{\min }+\rho \Delta_{\max }}{\Delta(k)+\rho \Delta_{\max }}
$$

In the Equation (I): $\Delta_{\mathrm{i}}(k)$ is the absolute difference between two comparison sequences at time $k, \rho$ is the resolution coefficient and $0 \leq \rho \leq 1$. In general, the value of $\rho$ is between 0.1 and 0.5 .

For a reference sequence $X_{0}$, there are several comparison sequences $X_{1}, X_{2}, \cdots$, $X_{N}$ the difference between the comparison curve and the reference curve can be expressed by the following relation [5]:

$$
\varepsilon(k)=\frac{\min \min || X_{0}(k)-X_{i}(k)|+0.5 \max \max | X_{0}(k)-X_{1}(k)||}{\| X_{0}(k)-X_{1}(k)|+0.5 \min \min | X_{0}(k)-X_{1}(k)||}
$$

In the Equation (II), $k=1,2,3, \cdots n ; i=1,2,3, \cdots, n ; \varepsilon_{\mathrm{i}}(k)$ is the correlation coefficient of $X_{i}$ to $X_{0}$ at time $k$.

The fourth step, calculate the degree of correlation. 


$$
R_{i}=\frac{1}{n} \sum_{k=1}^{n} \varepsilon_{i}(k)
$$

The fifth step, do the relevance ranking. Sort the size of $R_{i}$ to distinguish the size of their association. The larger the value of $R_{p}$ the greater the degree of association; the smaller the value of $R_{p}$ the smaller the degree of association.

\subsection{Determine the Analysis Sequence}

Select the time series data from 2005 to 2015 as the analysis object. The variables used in the article have industrial structure coefficient $\left(X_{0}\right)$, Total number of employees $(Y)$, First Industry Employment $\left(X_{1}\right)$,Secondary industry employment $\left(X_{2}\right)$, Employment of tertiary industry $\left(X_{3}\right)$, in which the industrial structure coefficient $=$ (second industry output value + tertiary industry output value)/province GDP. That is, we put the industrial structure coefficient $\left(X_{0}\right)$ as a reference series, other indicators as a comparison sequence. The following Table 2 shows the original data series of Guangdong Province.

\subsubsection{Data Dimensionless}

In this paper, the original data is transformed by the initial value method. The results of the initial transformation are shown in the following Table 3.

\subsubsection{Calculate the Correlation Coefficient}

According to the calculation formula of the correlation coefficient. In order to eliminate the effect that the value of $\Delta_{\max }$ is too large and the value of the correlation coefficient $r$ is distorted, we choose $\rho=0.5$, the sequence of the correlation coefficients of each comparison sequence is shown in the Table 4.

\subsubsection{Calculate and Sort the Relevance}

The correlation between the factors used in the mean method is shown in the following Table 5. Where $R_{i}$ represents the degree of correlation of the curve $X_{i}$ to the reference curve $X_{0}$.

Table 2. The original data series of Guangdong Province.

\begin{tabular}{ccccc}
\hline$X_{0}$ & $Y$ & $X_{1}$ & $X_{2}$ & $X_{3}$ \\
\hline 0.936682778 & 5022.97 & 1609.89 & 1916.16 & 1496.92 \\
0.942373107 & 5177.02 & 1562.17 & 2015.88 & 1598.97 \\
0.946641613 & 5341.50 & 1562.19 & 2102.28 & 1677.04 \\
0.946379717 & 5471.72 & 1526.66 & 2172.93 & 1772.13 \\
0.949097449 & 5688.62 & 1514.04 & 2292.05 & 1882.53 \\
0.950322192 & 5870.48 & 1435.17 & 2487.25 & 1948.06 \\
0.949945705 & 5960.74 & 1427.34 & 2526.48 & 2006.92 \\
0.950177041 & 5965.95 & 1418.38 & 2509.69 & 2037.88 \\
0.952346699 & 6117.68 & 1405.06 & 2563.50 & 2149.12 \\
0.953298525 & 6183.23 & 1382.41 & 2560.65 & 2240.16 \\
0.954052701 & 6219.31 & 1375.15 & 2546.57 & 2297.58 \\
\hline
\end{tabular}


Table 3. 2005-2015 industrial structure and employment structure data column initialized results of Guangdong Province.

\begin{tabular}{cccccc}
\hline Year & $X_{0}$ & $Y$ & $X_{1}$ & $X_{2}$ & $X_{3}$ \\
\hline 2005 & 1 & 1 & 1 & 1 & 1 \\
2006 & 1.006075 & 1.030669 & 0.970358 & 1.052042 & 1.068173 \\
2007 & 1.010632 & 1.063415 & 0.970371 & 1.097132 & 1.120327 \\
2008 & 1.010352 & 1.089340 & 0.948301 & 1.134002 & 1.183851 \\
2009 & 1.013254 & 1.132521 & 0.940462 & 1.196168 & 1.257602 \\
2010 & 1.014561 & 1.168727 & 0.891471 & 1.298039 & 1.301379 \\
2011 & 1.014159 & 1.186696 & 0.886607 & 1.318512 & 1.340700 \\
2012 & 1.014406 & 1.187734 & 0.881042 & 1.309750 & 1.361382 \\
2013 & 1.016723 & 1.217941 & 0.872768 & 1.337832 & 1.435695 \\
2014 & 1.017739 & 1.230991 & 0.858698 & 1.336345 & 1.496513 \\
2015 & 1.018544 & 1.238174 & 0.854189 & 1.328997 & 1.534872 \\
\hline
\end{tabular}

Table 4. Correlation coefficient sequence.

\begin{tabular}{cccc}
\hline $\begin{array}{c}\text { The correlation } \\
\text { coefficient of the } \\
\text { total amount of } \\
\text { employees }\end{array}$ & $\begin{array}{c}\text { The correlation } \\
\text { coefficient of the number } \\
\text { of employed persons in } \\
\text { the primary industry }\end{array}$ & $\begin{array}{c}\text { The correlation } \\
\text { coeficient of the number } \\
\text { of employed persons in } \\
\text { the secondary industry }\end{array}$ & $\begin{array}{c}\text { The correlation } \\
\text { coficient of the number } \\
\text { employed persons in } \\
\text { the third industry }\end{array}$ \\
\hline 1.000000 & 1.000000 & 1.000000 & 1.000000 \\
0.912982 & 0.878489 & 0.848734 & 0.806059 \\
0.830170 & 0.864946 & 0.748984 & 0.701740 \\
0.765648 & 0.806059 & 0.676185 & 0.598007 \\
0.683890 & 0.779994 & 0.585261 & 0.513734 \\
0.626000 & 0.677072 & 0.476551 & 0.473665 \\
0.599396 & 0.669173 & 0.458844 & 0.441498 \\
0.598285 & 0.659259 & 0.466390 & 0.426541 \\
0.561942 & 0.641880 & 0.445615 & 0.381184 \\
0.547518 & 0.618796 & 0.447546 & 0.350251 \\
0.540297 & 0.610888 & 0.453922 & 0.333290 \\
\hline
\end{tabular}

Table 5. The degree of correlation of each factor.

\begin{tabular}{cccc}
\hline relevance degree in First industry & $R_{1}$ & $R_{1}\left(X_{0}, X_{1}\right)$ & 0.746051 \\
relevance degree in Second industry & $R_{2}$ & $R_{2}\left(X_{0}, X_{2}\right)$ & 0.600730 \\
relevance degree in Third industry & $R_{3}$ & $R_{3}\left(X_{0}, X_{3}\right)$ & 0.547816 \\
\hline
\end{tabular}

From the above table can be drawn, the degree of correlation ranked $R_{3}<R_{2}<$ $R_{1}$, indicating that the proportion of tertiary industry in Guangdong Province and the proportion of labor force employment is the most closely related to the primary industry, secondary industry second, the tertiary industry is the last one in Guangdong Province, and the current industrial structure is not entirely con- 
sistent, and the two are not coordinated, so there is still much room for improvement [6].

\section{Suggestions on the Healthy Development of Industrial Structure and Employment Structure in Guangdong Province}

First of all, we should continue to accelerate the process of urbanization, and continue to strengthen the social division of labor [7]. With the continuous development of social economy, the level of urbanization has also been improved at different levels. The continuous improvement of urbanization is the inherent requirement of the general rule of industrial structure transformation and upgrading, at the same time, it has the decisive influence on the transformation of employment structure and becomes an indispensable condition for the transformation of employment structure. The development of the tertiary industry needs to take the city as the carrier, relying on urbanization. Urbanization lagging down, narrowing the development of the tertiary industry space, which directly or indirectly seriously bound the economic development and employment capacity of the increase, making the labor force in the first industry and the tertiary industry to enter the more difficult to limit the rapid transfer of labor in the three industries to upgrade, resulting in the slow development of economic restructuring. Therefore, some policies and measures to encourage the expansion of small and medium-sized cities, both directly expand the city's infrastructure needs, indirectly drive the local government investment needs of public facilities, but also greatly ease the contradiction between urban and rural dual economic structure, so that part of the first rich of the farmers can come into the city, to drive the development of tertiary industry, improve the employment.

Second, we have to strengthen the quality of education and training of workers, to make them can adapt to changes in industrial structure needs [8]. The quality of the labor force has become the main factor restricting the optimization and upgrading of the employment structure. The unbalanced development of industrial structure and employment structure in Guangdong Province can also be said to be the result of differences in human capital. The government should overcome all the obstacles to increase investment in education and actively encourage social forces to run schools. And we should strengthen the existing educational resources and facilities management and effective integration, to develop effective policy measures and scientific development index system, so as to promote the development of colleges and universities for the existing industrial structure trends in the professional settings, teaching content, teaching methods and other major modules to adapt to adjust to meet the future development of the professional skills of talent needs. In addition, we can take a variety of job training methods, the laid-off workers and rural surplus labor force job skills training to improve the practitioners of knowledge, skills and other aspects of the overall quality and improve human capital to improve the turnover of workers, so that a part of the staff can change into the second and third industry 
labor force, to improve the second and third industry practitioners proportion. And finally we can try to strengthen the introduction of high-end talent.

Third, continue to optimize the internal structure of the three industries [9]. Although the development of the tertiary industry in our province is relatively rapid, but from the internal structure of the tertiary industry, the developed countries mainly is information, consulting, science and technology, finance and other emerging industries, but the province of these emerging industries is greater employment flexibility industry. The province is still the traditional business, service industry, and some basic tertiary industry and emerging tertiary industry development is still insufficient, so the poor the internal structure of the current tertiary industry in the province is also a major cause of low labor employment.

Finally, we should to establish the correct employment concept of college students, to solve the problem of college students' employment. College students should pay attention to the cultivation of their own skills in practice during school. According to the above analysis, we can see that the employment direction of college students should be biased towards the tertiary industry service industry. From the structural deviation point of view, the tertiary industry still exists a lot of employment space, the labor force also has a strong absorption. Choosing the tertiary industry can help solve some of the difficulties of employment of college students. At the same time, they should strengthen their own quality training and practical ability to improve their own employment competitiveness, for the transformation and upgrading of employment structure to contribute their own strength.

\section{Conclusion}

This paper mainly through the Guangdong employment structure and industrial structure of the discussion and data analysis to find the relationship between the two. And on the basis we have found that the employment structure lags behind the industrial structure, and we have also found that the relationship between the employment structure and industrial structure is uncoordinated. These problems have a very negative effect on the upgrade and transformation of the industrial structure and employment structure in Guangdong Province. Therefore, we must continue to accelerate the process of urbanization, strengthen the social division of labor, followed by strengthening the quality of education and training of workers, the third continue to optimize the internal structure of the three industries, and finally establish the correct employment concept of college students. From these aspects to coordinate the relationship between the two, the two promote each other, and jointly promote economic development.

\section{References}

[1] Kuznets, S.S. (1989) Modern Economic Growth. Beijing University of Economics Press, Beijing.

[2] Liu, X.J. and Jiang, M.Y. (2016) Research on the Interactive Relationship between 
Industrial Structure and Employment Structure in the Western Triangle Economic Zone. Resource Development and Market, 2, 192-195.

[3] Chen, Z.C. and Zhang, Z.Y. (2016) Economic Opening, Financial Development and Changes in Employment Structure in the Western Region. China Science and Technology Forum, 5, 109-115.

[4] Deng, Z.L. (2002) Gray Theory Foundation. Huazhong University of Science and Technology Press, Wuhan.

[5] Wang, Q.L. (2015) Analysis on Gray Relational Grade of Industrial Structure, Employment Structure and Higher Education in Henan Province. Special Zone Economy, 7, 101-102.

[6] Xu, J. (2013) Analysis of Gray Correlative Degree of Agricultural Industrial Structure in Jilin Province. Enterprise Journal, 23, 159-160.

[7] Feng, Y. (2011) Analysis of Gray Relational Grade of Industrial Structure and Employment Structure in Liaoning Province. Journal of Shenyang Normal University, $35,35-37$.

[8] Yin, F. (2011) An Empirical Study on the Gray Correlation of Industrial Structure and Employment Structure in Hebei Province. China Environmental Management Institute, 21, 33-37.

[9] Wang, Q.F. (2010) A Review of the Research on the Coordinated Development of Industrial Structure and Employment Structure in China. East China Economic Management, 24, 14-149.

\section{Submit or recommend next manuscript to SCIRP and we will provide best} service for you:

Accepting pre-submission inquiries through Email, Facebook, LinkedIn, Twitter, etc. A wide selection of journals (inclusive of 9 subjects, more than 200 journals)

Providing 24-hour high-quality service

User-friendly online submission system

Fair and swift peer-review system

Efficient typesetting and proofreading procedure

Display of the result of downloads and visits, as well as the number of cited articles

Maximum dissemination of your research work

Submit your manuscript at: http://papersubmission.scirp.org/

Or contact jhrss@scirp.org 